\title{
Nothing But the Truth? Experiments on Adversarial Competition, Expert Testimony, and Decision Making
}

\author{
Cheryl Boudreau and Mathew D. McCubbins*
}

\begin{abstract}
Many scholars debate whether a competition between experts in legal, political, or economic contexts elicits truthful information and, in turn, enables people to make informed decisions. Thus, we analyze experimentally the conditions under which competition between experts induces the experts to make truthful statements and enables jurors listening to these statements to improve their decisions. Our results demonstrate that, contrary to game theoretic predictions and contrary to critics of our adversarial legal system, competition induces enough truth telling to allow jurors to improve their decisions. Then, when we impose additional institutions (such as penalties for lying or the threat of verification) on the competing experts, we observe even larger improvements in the experts' propensity to tell the truth and in jurors' decisions. We find similar improvements when the competing experts are permitted to exchange reasons for why their statements may be correct.
\end{abstract}

\footnotetext{
*Address correspondence to Cheryl Boudreau, University of California, Davis, Department of Political Science, One Shields Ave., Davis, CA 95616; email: clboudreau@ucdavis.edu. Boudreau is Assistant Professor of Political Science, University of California, Davis. McCubbins is Chancellor's Associates Chair of Political Science, University of California, San Diego; Visiting Professor of Law, University of Southern California; Adjunct Professor of Law, University of San Diego.

This article was presented at the Conference on Empirical Legal Studies at New York University, 2007. We thank Jennifer Arlen, Geoffrey Miller, and Ted Eisenberg for their generous invitation to present our work at that conference. We also thank the National Science Foundation, Grant SES-0616904, the Kavli Institute for Brain and Mind, and the Chancellor's Associates Chair VII at UC San Diego for providing financial support for these experiments. We are also grateful to William Heller, Scott Mackenzie, Rebecca Morton, Jeff Rachlinski, Dan Rodriguez, Joel Sobel, Matthew Spitzer, Jeff Staton, Lydia Tiede, and members of the University of San Diego Law School for helpful comments on an earlier draft of this article.
}

(C) 2008, Copyright the Authors

Journal compilation (C) 2008, Cornell Law School and Wiley Periodicals, Inc. 
"[J]urors sitting in a civil case frequently encounter not only one but severalusually conflicting-presentations of expert testimony."

Kutnjak Ivkovic and Hans (2003:478)

"[The] central precept of [the] adversary process is that out of the sharp clash of proofs presented by adversaries in a highly structured . . . setting is most likely to come the information from which a neutral ... decision maker can resolve a litigated dispute."

Landsman (1983:714)

In many legal, political, and economic contexts, people must make decisions about which they are not fully informed. Because people typically lack the opportunity and/or inclination to gather detailed information about these decisions for themselves, they must often base their decisions on the statements of others (Sniderman et al., 1991; Lupia, 1992, 1994; Mondak, 1993; Lupia \& McCubbins, 1998; Boudreau, 2006). For example, when deciding a question at trial, jurors must rely on the statements of competing attorneys and their witnesses. Or, when choosing among different candidates for office, uninformed voters may rely on the statements of politicians competing in a debate and on the endorsements of trusted allies. Similarly, when choosing among products, consumers often rely on information provided by competing sellers and on the opinions of trusted endorsers, such as Consumer Reports, the Better Business Bureau, Good Housekeeping, and Morningstar.

A key feature of the above contexts is competition between experts (who may be attorneys, witnesses, politicians, or sellers). Although much research in economics and political science suggests that competition does not necessarily produce beneficial outcomes (Crawford \& Sobel, 1982; Austen-Smith, 1990a, 1990b, 1993; Lupia \& McCubbins, 1998 ), there is a long-standing debate in legal scholarship over the use of expert testimony in courtroom settings. Specifically, some scholars fear that our adversarial legal system does not necessarily reveal truthful information and allow jurors to make informed decisions (Pound, 1906; Frank, 1945; Tullock, 1975, 1980; Bundy \& Elhauge, 1991; Kaplow \& Shavell, 1989). On the other hand, several scholars suggest that competition between experts in a courtroom will lead to the revelation of truthful information (Milgrom \& Roberts, 1986; Lipman \& Seppi, 1995; Froeb \& Kobayashi, 1996).

Given the disagreement among scholars about the effects of competition, we use laboratory experiments to assess whether and when competition induces experts to make truthful statements and enables jurors to learn from 
these statements and improve their decisions. ${ }^{1}$ Contrary to expectations from cheap-talk games (Crawford \& Sobel, 1982; Lupia \& McCubbins, 1998) and contrary to critics of our adversarial legal system, our experiments demonstrate that competition between experts does in fact help subjects to improve their decisions. This result is surprising because, in our experiments, subjects receive statements from two competing experts, but they do not know which expert has an incentive to tell them the truth and which expert does not. Thus, as in cheap-talk models, subjects cannot readily distinguish true statements from lies. In such situations, subjects should ignore the experts' statements and make their decisions on their own (see, e.g., Lupia \& McCubbins, 1998), but this is not what we observe.

Specifically, we find that competition by itself (even when it is cheap talk) induces enough truth telling from the experts to allow subjects to make better decisions than subjects in a control group who make decisions without the benefit of experts' statements. Importantly, our results show that the positive effect of competition is driven by those instances in which both competing experts make truthful statements to subjects. Rather than viewing the experts' statements as cheap talk and ignoring them (as expected), subjects appear to rely on a simple (and effective) rule of thumb. Namely, assume that when both experts make the same statements, they must be telling the truth. This rule of thumb turns out to be quite helpful, as it enables subjects to improve their decisions even when they are exposed to competing experts that do not both have an incentive to be truthful.

When we impose additional institutions (such as a penalty for lying or a threat of verification) on the competing experts, we find that these additional institutions frequently increase the experts' propensity to make truthful statements and enable subjects to achieve even larger improvements in their decisions. Interestingly (and somewhat surprisingly), we find that, for the range of penalties we examine, smaller penalties for lying can be just as effective as large ones at increasing the experts' propensity to tell the truth and helping subjects to improve their decisions. Further, our results show that adding a small penalty for lying to the threat of verification dramatically increases the extent to which verification induces the experts to make truthful statements and helps subjects to improve their decisions.

\footnotetext{
'We refer to the people receiving the competing experts' statements as jurors throughout this article. That said, the lessons about the effects of competition also apply to voters and consumers who receive the statements of competing experts in political and economic contexts.
} 
When the competing experts have an opportunity to exchange reasons with one another, subjects are also able to improve their decisions. This improvement occurs despite the absence of additional institutions in this treatment condition and the fact that the exchange of reasons does not increase the experts' propensity to tell the truth. Indeed, although subjects in this experimental condition always receive conflicting statements from the experts, the exchange of reasons helps them improve their decisions, over and above the improvements subjects achieve when the competing experts do not exchange reasons with one another. This result is quite interesting, given that the competing experts' exchange of reasons is still cheap talk and should not (and indeed does not) increase the experts' propensity to tell the truth. Thus, it appears that the improvements in subjects' decisions are driven by the experts' reasons alone, and not by an increase in truth telling.

This article proceeds as follows. We begin by describing our experimental design, which exposes subjects to the statements of two competing experts before they must make their decisions. Then, we make predictions regarding whether and under what conditions (1) the experts will be more likely to make truthful statements and (2) subjects receiving the experts' statements will improve their decisions. Next, we present our experimental results. We conclude with a discussion of the implications that our results have for debates about the effects of competition in legal, political, and economic contexts. Specifically, we emphasize that because competition in our adversarial legal system (and in many political and economic settings) incorporates penalties for lying, verification, and the exchange of reasons, our results suggest that testimony from competing experts can in fact lead to large improvements in decision making.

\section{The Debate: Does Competition Between Experts Help JuRORS LEARN?}

For decades, scholars have extolled the virtues of competition, arguing that we should incorporate more competitive practices into our legal, political, and economic systems. This idea that competition will produce beneficial outcomes is supported by a long line of theoretical and empirical research suggesting that competition between actors leads to the exposure or verification of false statements and, therefore, reveals truthful information and improves decision making (Milgrom \& Roberts, 1986; Lipman \& Seppi, 1995; Froeb \& Kobayashi, 1996; Freedman, 1975; Kim, 2001; Walpin, 2003). 
For example, Milgrom and Roberts (1986) demonstrate that an unsophisticated decisionmaker will make a fully informed decision as long as the interests of the competing litigants are sufficiently opposed.

On the other hand, many scholars caution that competition is beneficial only under certain conditions and that it may even have negative effects (Pound, 1906; Frank, 1945; Tullock, 1975, 1980; Frankel, 1980; Langbein, 1985; Bundy \& Elhauge, 1991; Kaplow \& Shavell, 1989; Shin, 1998; Posner, 1999; Daughety \& Reinganum, 2000; Lupia \& McCubbins, 1998; Weigend, 2003; Sniderman \& Theriault, 2004; Chong \& Druckman, 2007). Further, research in cognitive science, political science, and economics questions the assumption (implicit in many arguments in favor of competition) that jurors listen to competing experts, as well as trust and learn from the information that they offer. Indeed, the cognitive science literature emphasizes that listening and learning are costly behaviors, at least insofar as people must forego the opportunity to do other things while they listen and learn (Jackendoff, 1980; for a survey, see Lupia \& McCubbins, 1998; Lupia, 2002; McCubbins \& Rodriguez, 2006). ${ }^{2}$ Further, because humans have limited time and energy, they are able to pay attention to and remember only a small fraction of the information available to them (Schacter, 2001; Lupia, 2004; Lupia \& McCubbins, 1998). And, as the political science and economics literatures demonstrate, "talk is cheap"; that is, without some cost associated with making false statements, there is no way to ensure that competing experts tell the truth (Crawford \& Sobel, 1982; Austen-Smith, 1990a, 1990b, 1993; Lupia \& McCubbins, 1998).

It is this research on the effects of competition that we build on in this study. Specifically, we draw on the insights of Lupia and McCubbins (1998) and the experimental design of Boudreau (2006) to analyze the conditions under which competition between two experts consistently induces both experts to make truthful statements and enables jurors to trust those statements and, thereby, improve their decisions. Although there are many theoretical, experimental, and empirical studies of competition, our experimental

\footnotetext{
${ }^{2}$ McCubbins and Rodriguez (2006) conduct experiments in which subjects can receive information from others, either for free or after paying a cost. Their results demonstrate that when listening is free, 97 percent of subjects choose to receive information from others. When there is a small cost to receive information, the percentage of subjects that choose to receive information drops to 50 percent. When a larger cost is imposed, only 4 percent of subjects choose to receive information. Taken together, these results demonstrate that people are less willing to listen to information from others when there is a cost associated with doing so.
} 
design makes a number of new contributions to the literature and has several important advantages.

The first advantage of our design stems from the nature of the choices that subjects make in our experiments. Specifically, instead of asking subjects to make decisions about fictional court cases or to vote for fictional candidates (as psychologists, legal scholars, and political scientists often do when running experiments), we ask subjects to make choices about math problems after they hear two expert subjects make statements about whether answer "a" or answer "b" is the correct answer. (Note that the two subjects who are chosen to be the experts are shown the correct answer to a particular math problem before they make their statements; thus, they are made expert by the experimenter. This is common knowledge to all participants in the experiment.) One reason that this type of decision is advantageous is that solving math problems provides a straightforward way to identify correct decisions and to assess whether and when the experts' statements induce an improvement in decision making. Stated differently, although it is often difficult to identify when jurors have chosen the "correct" legal decision or candidate, ${ }^{3}$ it is very easy to tell when they have chosen the correct answer to a math problem. Similarly, because we know the correct answer to each math problem and show that answer to the competing experts, we can easily identify whether and when the experts tell the truth.

The second advantage of our design is that math problems, even though they do not look like legal or political decisions on the surface, capture many key characteristics of the information that jurors receive and the decisions that jurors make in real-world competitive contexts. Thus, they can tell us a great deal about how jurors in the real world make choices. For example, in real-world competitive contexts, jurors are not blank slates when they listen to the statements of experts. That is, they often have preexisting knowledge or beliefs about the topics that the experts discuss. Similarly, subjects in our experiments are not blank slates when they hear the experts' statements about whether answer "a" or answer " $b$ " is the correct choice because they have preexisting knowledge about how to solve math problems.

\footnotetext{
${ }^{3}$ See Seidman Diamond (2003) for a discussion of the difficulties associated with identifying whether and when jurors make "correct" decisions. Indeed, she states: "To assess how the jury operates as a decision-maker, we cannot compare the jury's verdict with some gold standard of truth because no such dependable standard exists ... [I]n the end we cannot be certain that the correct conclusions have been drawn" (2003:150-51).
} 
That said, jurors in the real world might be uncertain about their decisions; that is, they may not know which choice (e.g., guilty vs. not guilty) is the correct one. Similarly, subjects in our experiments may be uncertain about whether "a" or " $\mathrm{b}$ " is the correct choice. As in the real world, the uncertainty that subjects experience depends, in part, on their levels of sophistication. Indeed, just as unsophisticated jurors in the real world may be more uncertain about which choice is correct, so, too, may unsophisticated subjects in our experiments be more uncertain about whether "a" or " $b$ " is the correct choice. And, just as jurors in the real world vary in their levels of sophistication, so, too, do our subjects, as their SAT math scores range from 450 (the 27th percentile) to 800 (a perfect score).

Further, in real-world competitive contexts, there is something at stake for jurors when they make their decisions, but the stakes may not be very large. This is especially true in low-profile, run-of-the-mill court cases. Similarly, there is something at stake for subjects in our experiments because they earn money if they make a correct choice and lose money if they make an incorrect choice. As is the case in many real-world settings, the stakes in our experiments are not very large, as subjects either earn or lose 50 cents for each decision they make.

Further, jurors in real-world competitive contexts often receive factual information, and they must then make decisions that are objectively correct or incorrect. For example, in courtroom settings, jurors listen to factual information that competing witnesses provide and then make a decision about whether the accused is guilty or innocent or whether a party to a civil suit is liable or not. Interestingly, in both criminal and civil trials, jurors are often exposed to mathematical information that is not unlike the information that subjects in our experiments receive (Lilly, 2001; Fisher, 20002001). ${ }^{4}$ Like jurors in the real world, subjects in our experiments receive factual, mathematical information and then make decisions that are either correct or incorrect. Given the many similarities between real-world legal and political decisions and decisions about math problems, there is a close mapping between the psychological processes that occur in our experiments and the psychological processes used by jurors in real-world competitive

\footnotetext{
${ }^{4}$ Indeed, Lilly (2001:71) states: "[W]ith increasing frequency, contemporary juries are faced with sophisticated, highly technical evidence drawn from such diverse fields as economics, mathematics, statistics, psychiatry, engineering, epidemiology, toxicology, serology, and genetics."
} 
contexts (stated differently, our experiments have a great deal of psychological realism; see Aronson et al., 1998).

\section{EXPerimental Design}

To shed light on debates about the effects of competition, we conduct laboratory experiments. To this end, we randomly assign subjects to either a control group or to one of several different treatment groups. We then ask subjects in all groups to answer binary-choice math problems that are drawn from an SAT math test and consist of several different types of problems and various levels of difficulty. We tell subjects in both our treatment and control groups that they have 60 seconds to answer each math problem and that they will earn 50 cents for each problem they answer correctly, lose 50 cents for each problem they answer incorrectly, and neither earn nor lose 50 cents if they leave a problem blank.

The main difference between the treatment and control groups has to do with the conditions under which subjects answer the math problems. In the control group, subjects answer the math problems on their own, one at a time. The purpose of the control group is to establish a baseline for how well subjects perform on the math problems when they must make their choices on their own (i.e., without an opportunity to learn from two competing experts' statements).

In our various treatment groups, subjects answer subsets of the math problems that subjects in the control group answer; ${ }^{5}$ however, subjects in the treatment groups receive the statements of two competing experts before they make their decisions. Specifically, before each math problem, the experimenter selects two subjects at random to act as the experts for that particular math problem. The experts are then shown the correct answer to a particular math problem (i.e., the experts are given knowledge about the correct choice), and they then choose what statement they

\footnotetext{
${ }^{5}$ Subjects in the control group answer 24 math problems. Because it takes a great deal of time to explain particular treatment conditions to subjects and select two subjects to act as the experts for each math problem, we were unable to have subjects answer 24 math problems in each treatment condition. Thus, subjects in each treatment condition answer subsets of the math problems that subjects in the control group answer. We control for the difficulty of the math problems in our statistical analyses to ensure that our results are not driven by differences in the difficulty of the math problems used in each treatment condition and in the control group.
} 
would like to make to subjects (statements take the form of answer "a" or answer "b"). Once the experts choose their statements, the "testimony" of the two experts is passed on to the remaining subjects (either on a single sheet of paper or read aloud) ${ }^{6}$ In either case, subjects receive a joint statement from the experts (e.g., "a, a"; "b, b"; "a, b"). Then, subjects must decide within 60 seconds whether to answer the problem, and if they choose to answer, whether to pick "a" or "b."

Once subjects make their decisions, we move on to the next math problem. At this point, we randomly select two new subjects to act as the experts. ${ }^{7}$ We select two new subjects for each math problem to ensure that the competing experts do not develop reputations from one problem to the next. ${ }^{8}$ Indeed, avoiding repeat-play effects is important because such effects could confound the treatments we impose. Further, because jurors' interactions with competing experts typically do not repeat over time (e.g., they are typically limited to the course of a trial), it makes sense to have subjects make "one-shot" decisions in our experiments. ${ }^{9}$

That said, the key to our experimental design is threefold. First, one of the experts knows that he or she shares common interests with subjects (i.e., he or she benefits when the remaining subjects answer the math problem correctly), and the other expert knows that he or she has conflicting interests

\footnotetext{
${ }^{6}$ Note that the experimenter reads both experts' statements aloud to the subjects in order to prevent subjects from learning anything about the experts from the sound of their voices. Also, all subjects (including the experts) sit behind partitions so that their identities are anonymous. Note also that we do not actually refer to the experts as "experts" in the experiments. We simply refer to them as the reporters.
}

${ }^{7}$ In some experiments, we randomly select two new subjects to act as the experts by pulling two subject numbers out of a hat before each math problem. In other experiments, we randomly select four or more subjects at the beginning of the experiment to act as a panel from which we draw two competing experts on any particular math problem. Then, before distributing each math problem, we draw two numbers out of a hat to determine which two subjects on the panel will act as the experts on that problem. We repeat this procedure for each math problem.

${ }^{8}$ The total number of math problems that any one subject (acting as an expert) makes statements about depends on which procedure is used to select the experts, as well as the number of math problems used in a particular experiment. Across all experiments, the total number of math problems that an expert makes statements about ranges from 14 problems to 1 problem. Also, subjects answer between 5 and 24 math problems in each experiment. We control for this in our statistical analyses, and it does not affect our results.

${ }^{9}$ For an example of a repeated communication game, see Sobel (1985). 
with subjects (i.e., he or she benefits when the remaining subjects answer the math problem incorrectly). We refer to these as the common-interest and conflicting-interest experts, respectively. Second, it is common knowledge to all subjects that one expert shares common interests with them and that one expert has conflicting interests with them, but they are not told which expert shares common interests with them on any particular problem. Stated differently, subjects know that the experts are adversaries, but they do not know which expert's interests are aligned with their own. ${ }^{10}$ Third, both experts and the subjects know that the experts can lie about the correct answer to the math problem or they can tell the truth; it is entirely up to them. The experts' ability to make whatever statement they wish is constant throughout this experiment and is designed to be an analogy to Crawford and Sobel's (1982) and Lupia and McCubbins's (1998) models, as well as to many real-world competitive settings.

So how do we induce competition between the two experts within the context of our experiments? In short, we induce competition by manipulating the ways that the experts and the subjects earn money. Specifically, the common-interest expert is paid 50 cents for each subject who answers a particular math problem correctly. The conflicting-interest expert is paid 50 cents for each subject who answers a particular math problem incorrectly. So, for example, if 11 subjects (the typical number used in our experiments) answer the math problem correctly, they earn 50 cents each, the common-

\footnotetext{
${ }^{10} \mathrm{We}$ design our experiments in this way because we are interested in analyzing the conditions under which jurors can learn from competing experts who they do not know. This aspect of our experiments corresponds to many legal and political settings. Indeed, when learning from competing experts in a courtroom, jurors may not know which expert's interests are aligned with their own. Similarly, in primary elections, voters may not know which candidate (of the many candidates who share their party label) is more likely to have interests that are aligned with their own. That said, we could design our experiments differently. Indeed, if we were interested in analyzing the conditions under which jurors can learn from competing experts who they know something about, we could tell subjects that there is a 70 percent chance that the second expert has conflicting interests with them. Because the two experts in our experiments are adversaries, this means that subjects would also know that there is a 70 percent chance that the first expert has common interests with them. Knowing this, subjects should ignore the second expert's statement, pay attention to the first expert's statement, and base their choices on it. However, because this design simply turns our experiments into a test of how perceived common interests between an expert and a juror affect trust, persuasion, and learning, and because the effects of common interests are well understood (see Lupia \& McCubbins, 1998 for a game theoretic model and experiments demonstrating the effects of common interests, which work as expected), we focus instead on situations in which subjects do not know which expert is more likely to share common interests with them on any particular problem.
} 
interest expert earns $\$ 5.50$ (i.e., 50 cents for each of the 11 subjects who answer the problem correctly), and the conflicting-interest expert loses $\$ 5.50$ (i.e., 50 cents for each of the 11 subjects who answer the problem correctly). Similarly, if 11 subjects answer the math problem incorrectly, then the common-interest expert loses $\$ 5.50$, and the conflicting-interest expert earns $\$ 5.50$. In this way, the interests of the two competing experts are strictly adversarial, or zero sum.

In addition to the competition treatment condition described above, we impose several other treatments in our experiments. In these additional treatment conditions, we alter the basic competition condition in one of two ways: (1) following Lupia and McCubbins (1998), we vary the institutional context in which the competing experts make their statements or (2) we allow the competing experts to exchange reasons for why "a" or " $b$ " may be the correct choice for subjects. Each of these experimental variations is common knowledge at the outset of each treatment. The details of how we implement these additional treatment conditions are described below.

\section{A. Additional Institutional Conditions}

In other treatment conditions, we alter the basic competition condition by imposing one of two additional institutions on the competing experts: namely, a penalty for lying or a threat of verification. Both of these additional institutional conditions have analogues in real-world competitive contexts. Specifically, in legal contexts, jurors know that witnesses for both the prosecution and the defense face penalties for perjury if they lie on the stand. Similarly, an expert witness may incur a penalty for lying (in the form of a loss of reputation) if he or she is caught lying while testifying during a trial. Similarly, attorneys' cross-examinations are a form of verification that may reveal when witnesses have made false statements.

To impose a penalty for lying in our experiments, we simply manipulate the way that the experts earn money. Specifically, we maintain the competition between the two experts, but we subtract money from the experts' experimental earnings each time they make a false statement. So, in the penalty for lying treatment conditions, the experts are engaged in competition as before, but we announce to the experts and the subjects that both experts will incur a penalty (either a large $\$ 15$ penalty or a smaller $\$ 5$ or $\$ 1$ penalty, depending on the experimental condition) if they lie about the correct answer to the math problem. We vary the size of the penalty because penalties for lying in real-world courtroom settings also vary in how large 
they are, relative to what is at stake for the experts. For example, the $\$ 15$ penalty for lying is a very large penalty, relative to what is at stake for the experts in our experiments. The $\$ 1$ penalty, however, is small relative to the money the experts can gain in our experiments. Indeed, the conflictinginterest expert can gain as much as $\$ 5.50$ if 11 subjects choose the wrong answer to a problem and lose only $\$ 1$ for lying about the correct answer. Similarly, the penalties for lying that experts in real-world courtroom settings face can be large or small, depending on the nature of the trial, the stakes involved, and the value that the expert places on his or her reputation.

For the other institution-namely, verification-we again maintain competition between the two experts, but this time we verify both experts' statements with some probability to make sure that they are true statements before they are provided to subjects. In the high (i.e., 100 percent) chance of verification condition, if either expert chooses to make a false statement about the correct answer to the math problem, we do not provide the false statement(s) to subjects, but rather replace it (them) with the correct answer when we provide the experts' statements. If either expert makes a true statement, then we simply provide that expert's statement to subjects.

However, because a 100 percent chance of verification is unlikely to occur in real-world courtroom settings, we also examine the effects of a smaller, 50 percent chance of verification. In the 50 percent chance of verification condition, we roll a six-sided die before the experts' statements are provided to subjects. If the die lands on 1 through 3 , then we silently verify both experts' statements and replace any false statements with truthful statements when we provide the experts' statements to subjects. If the die lands on 4 through 6 , however, then we simply provide the answers that the experts choose to report, regardless of whether they are correct or incorrect. In this way, subjects know that there is a 50 percent chance that the experts will be verified, but they do not know whether a particular expert has been verified on any particular problem.

To make our verification and penalty for lying conditions even more realistic, we add a conditional penalty for lying to the threat of verification. We do this because, in the real world, experts must often pay a cost if they are verified and caught lying. Further, experts' false statements are not likely to be detected or punished with certainty in real-world courtroom settings. Thus, in these experimental conditions, the competing experts must pay a cost (of either $\$ 1$ or $\$ 2$, depending on the experimental condition) if they 
make a false statement and are verified by the experimenter. In this way, the penalty is conditional (and is different from the penalty for lying treatment conditions described above) because it is only imposed if verification occurs. For example, in the 50 percent chance of verification plus a $\$ 1$ penalty condition, both experts lose $\$ 1$ of their experimental earnings if the die lands on 1 through 3 (i.e., verification occurs) and if they had chosen to make a false statement. However, if the die lands on 4 through 6 (i.e., verification does not occur) and if both experts had chosen to make false statements, then we do not subtract $\$ 1$ from the experts' experimental earnings, and we provide the experts' false statements to subjects. The other experimental conditions in which we impose a chance of verification plus a conditional penalty proceed in a similar manner.

\section{B. Reason-Giving Conditions}

In our reason-giving treatment conditions, we alter the basic competition condition by allowing the competing experts to exchange reasons for why "a" or "b" may be the correct choice. These experiments are identical to the basic competition treatment condition (i.e., competition without additional institutions) with four exceptions. First, the competing experts are no longer required to make statements about whether " $a$ " or " $b$ " is the correct choice; that is, both experts can choose to remain silent. Second, if either expert chooses to make a statement, he or she must not only state whether " $a$ " or " $b$ " is the correct choice, but must also give a reason for why the answer he or she chooses to report may be correct. Third, the experts have an opportunity to respond to one another's statements and reasons; that is, the experts have three opportunities to give reasons and counterreasons. Fourth, in some of our reason-giving treatments, the competing experts must pay a small cost (\$1) each time they wish to give a reason and recommend an answer. Thus, competition between experts in these reason-giving conditions is analogous to the testimony given to juries, where witnesses may be called to rebut one another's statements and attorneys may counter the arguments made by opposing counsel. ${ }^{11}$

\footnotetext{
"As Vidmar and Seidman Diamond (2001:1133-34) note: "The adversary system relies on the opposing side to cross-examine and deconstruct the testimony of the expert to expose its weakness or irrelevance to the dispute. Then, the first party is allowed to reexamine its experts to rehabilitate them. When the opposing party begins its evidence presentation, it may call its own experts in an effort to refuce the other party's experts. The end result of the adversary process is often conflicting testimony from experts-the 'battle of the experts."
} 
Specifically, our reason-giving experiments proceed as follows. After both experts are shown the correct answer to a math problem, the first expert chooses whether to make a statement to the other subjects about whether "a" or " $\mathrm{b}$ " is the correct answer (in some treatments, both experts may make a statement for free, while in other experiments they must pay $\$ 1$ each time they wish to make a statement). If the first expert chooses to make a statement, then he or she must decide whether to state "a" or "b." After the first expert selects which answer to report, then he or she must also select a reason for why the answer that he or she chose may be correct. When selecting a reason to support his or her statement of "a" or "b," the first expert may choose from a brief menu of correct and incorrect reasons that we provide or write down his or her own reason. As before, the first expert's statement and reason may truthfully reflect the correct answer or falsely indicate a different answer. After the first expert selects a statement and reason, we distribute that statement and reason to the second expert. If the first expert chooses not to make a statement, then we tell that to the second expert and see whether the second expert wishes to make a statement and give a reason.

The second expert then chooses whether to make a statement. If the second expert chooses to make a statement, then he or she must decide whether to recommend "a" or " $b$ " to subjects. After choosing his or her statement, the second expert must then provide a reason for the answer that he or she chose. When selecting a reason to support his or her statement of "a" or "b," the second expert may also choose from the list of correct and incorrect reasons that we provide or write down his or her own reason. We then distribute this statement and reason to the first expert. If the second expert chooses not to make a statement, then we tell that to the first expert and see whether the first expert would like to make another statement.

We continue this process until both experts have had three opportunities to provide reasons for their recommended answer. Although both experts can choose up to three reasons for why their recommendation of "a" or " $b$ " may be correct, the experts cannot change their statement on a particular math problem. That said, they can repeat the same reason over and over, or they can choose a new reason each time. In this way, we allow the competing experts to go back and forth about whether "a" or " $b$ " is the correct choice for subjects and about why "a" or " $b$ " may be correct or why the other expert may be wrong. At the end of the trial, we allow the subjects to see a transcript of the experts' exchange of statements and reasons. That is, we have the two experts debate first, and we then distribute the transcript 
of the debate in order to save time and reduce subject boredom. It also allows us to maintain the anonymity of the experts, as subjects are not allowed to hear them, see their writing (except after we transcribe it), or have any other contact or communication with the experts. We then give subjects 60 seconds to choose an answer to the math problem.

\section{HYPOTHESES}

For several of the experimental conditions described above, we make predictions about (1) the competing experts' propensity to make truthful statements and (2) subjects' ability to make better decisions than subjects in the control group (who do not receive the experts' statements). We measure the quality of subjects' decisions in two ways. First, we observe the amounts of money that subjects earn in the treatment and control groups. Indeed, because all subjects earn money for correct answers, lose money for incorrect answers, and neither earn nor lose money for blank answers, the relative amounts of money that subjects earn is a straightforward measure of whether competition (with or without additional institutions or the exchange of reasons) helps subjects to improve their decisions. Second, we observe the accuracy of subjects' decisions in the treatment and control groups. This measure reflects whether subjects answer a particular problem correctly in each experimental condition. ${ }^{12}$

In the basic competition condition, we predict that the decisions of subjects exposed to the competing experts will be no different than the decisions of subjects in the control group. The logic behind this prediction can be understood by comparing the basic competition condition to cheaptalk models (e.g., Crawford \& Sobel, 1982; Lupia \& McCubbins, 1998). Specifically, in Lupia and McCubbins's (1998) formulation, a speaker makes a statement to a listener, and the speaker's and listener's payoffs are determined, in part, by what the listener does. In their model (and in our experiments), the speaker may make a statement to the listener, such as pick choice " $a$ " or pick choice "b." When the listener does not know whether the

\footnotetext{
${ }^{12}$ The main difference between these two measures is how blank answers are coded. Specifically, the money earned measure is coded as +50 cents for each correct answer, -50 cents for each incorrect answer, and 0 for each blank answer. The accuracy measure is coded as +1 for each correct answer and 0 for each incorrect answer and each blank answer. Our results are remarkably consistent across these two different measures.
} 
speaker is trustworthy (and cannot distinguish true statements from lies), there is no equilibrium in which the listener pays attention to the speaker's statements. Indeed, the listener should ignore the speaker's statements and make a decision on his or her own. However, when the listener knows that the speaker is trustworthy (e.g., when the listener knows that the speaker shares common interests with him or her) (see Lupia \& McCubbins, 1998), there exists an equilibrium in which the speaker makes a truthful statement and the listener pays attention to and trusts the speaker's statement.

The game between the experts and subjects in our basic competition condition is merely an extension of Lupia and McCubbins's (1998) model, where the speaker's interests are either unknown or known to conflict with those of the listener. Specifically, in our basic competition condition, one expert has common interests with subjects, and one expert has conflicting interests with subjects. Subjects can be seen as receiving a joint signal from these experts (e.g., they hear "a, a"; "b, b"; "a, b"), but they are not told which expert is more likely to share common interests with them, and they are uncertain about whether "a" or " $b$ " is the correct choice (and they can infer nothing from the order of the statements). Because subjects are not told which expert is more likely to share common interests with them, they cannot know which (if any) expert made a truthful statement about whether "a" or "b" is the correct choice. Thus, we expect subjects to ignore the competing experts' statements and make their decisions on their own (just like subjects in the control group who must also answer the problem on their own). ${ }^{13}$ In this way, our basic competition condition is identical to standard cheap-talk models, with the only exception being that the cheap talk in our experiments is composed of a joint statement-two signals, logically reducible to a single signal. ${ }^{14}$

\footnotetext{
${ }^{13}$ Lupia and McCubbins (1998) show that subjects ignore a speaker's statements when they do not know whether it is more likely than not that the speaker shares common interests with them. Specifically, they state: "[P]eople ignore stimuli that they do not expect to facilitate reasoned choices... [P] ersuasion requires the [citizen] to believe that the [expert's] statement will help her avoid costly mistakes. That is, persuasion does not occur if the [citizen] believes that the [expert] is likely to have conflicting interests. If, however, the [citizen] believes that common interests are more likely, then persuasion is possible" (1998:50).

${ }^{14}$ For readers who are familiar with basic economic principles and with Crawford and Sobel (1982), our predictions are not particularly surprising. That said, we do not know of anyone who has assessed experimentally whether the standard cheap-talk result holds up when there is more than one speaker.
} 
For example, if subjects in the basic competition condition receive the joint signal " $a, b$," they do not know which statement to trust because they are not told whether the expert who stated "a" or the expert who stated " $b$ " is more likely to share common interests with them. ${ }^{15}$ If subjects receive the joint signal "a, a," they still cannot learn from these statements because they do not know whether both experts made truthful statements or whether both experts made false statements. ${ }^{16}$ Specifically, because the commoninterest expert is strictly better off if subjects make correct decisions and the conflicting-interest expert is strictly better off if subjects make incorrect decisions, subjects should not be able to make an inference from receiving two of the same statements. Indeed, there is no reason for subjects to believe that the conflicting-interest expert would give up the chance to deceive them, but there is also no reason for them to believe that the commoninterest expert would give up the chance to tell them the truth.

Because subjects should ignore the experts' statements in the basic competition condition, we do not have any predictions regarding the experts' propensity to tell the truth in this condition. The reason we lack predictions is that, knowing that subjects will ignore their statements, both the common-interest and conflicting-interest experts can make either true or false statements, in equilibrium. ${ }^{17}$ Indeed, because subjects do not have an incentive to listen to their statements, the experts are, theoretically, just as well off if they choose their statements randomly, always tell the truth, or always lie.

\footnotetext{
${ }^{15}$ Of course, we expect more sophisticated subjects to be better able to infer the correct answer from conflicting statements. The reason for this prediction is that sophisticated subjects may be able to answer the problem correctly on their own and, therefore, self-verify the experts' statements. We test predictions about the interaction between sophistication, problem difficulty, and competition in future papers.
}

\footnotetext{
${ }^{16}$ However, if we were to assume that it is common knowledge that people always choose to tell the truth when they are indifferent between lying and telling the truth, then the commoninterest expert will always have a dominant strategy to tell the truth. In this situation, as long as subjects believe that the likelihood of mistakes is low, then upon hearing "a" twice, the subjects could infer that " $a$ " is the correct answer. If this is true, however, then the conflicting-interest expert will always lie (as long as speaking and lying are cost free). Thus, subjects, in equilibrium, will be unable to infer the correct answer from the conflicting pair of statements that they receive from the experts.

${ }^{17}$ Although there exist multiple equilibria, we are not surprised that subjects typically converge on the equilibrium in which the common-interest expert tells the truth and the conflictinginterest expert lies.
} 


\section{A. The Big Stick: Hypotheses About Large Penalties and High Probabilities of Verification}

When competition is combined with a large penalty for lying, we expect very different results. Specifically, when both competing experts are subject to a large (i.e., \$15) penalty for lying, we predict that the experts will be more likely to make truthful statements, relative to experts in the basic competition condition. We also expect that subjects who receive the competing experts' statements will make significantly better decisions than subjects in the control group.

The logic behind these predictions stems from Lupia and McCubbins's (1998) model, which demonstrates that when a penalty for lying is sufficiently large, then, in equilibrium, a speaker never has an incentive to lie, and the subjects trust and learn from the speaker's statements. In the context of our experiments, a $\$ 15$ penalty is "sufficiently large"-that is, it is large enough to ensure that both experts have a dominant strategy to tell the truth and that all subjects know this.

When competition is combined with a high chance of verification (say, at the extreme, 100 percent), we expect results that are similar to those in the large penalty for lying condition. Specifically, when both competing experts are subject to a high chance of verification (i.e., a 100 percent chance of verification plus a $\$ 1$ or $\$ 2$ penalty if they are caught lying), we predict that the experts will be more likely to make truthful statements, relative to experts in the basic competition condition. ${ }^{18} \mathrm{We}$ also expect that subjects who receive the competing experts' statements will make significantly better decisions than subjects in the control group. These predictions also stem from Lupia and McCubbins's (1998) model, which demonstrates that increasing the probability of verification decreases the probability that a speaker can benefit from making a false statement.

\footnotetext{
${ }^{18}$ We make this prediction about the experts' behavior because the experts are not only verified with certainty, but they also face a $\$ 1$ or $\$ 2$ cost if they are caught lying about the correct answer to the problem. We include a small cost in this experimental condition for two reasons. First, in real-world settings, experts must often pay a cost (be it a loss of reputation or monetary sanctions) if they are verified and found to be misrepresenting the truth. Second, the original experiments that tested the effects of verification also included a small cost in the verification condition (Lupia \& McCubbins, 1998).
} 


\section{B. Smaller Sticks: Reduced Penalties and Lower Chances of Verification}

As for the smaller penalties for lying and smaller chances of verification that we impose in our experiments (i.e., a $\$ 5$ penalty, a $\$ 1$ penalty, and a 50 percent chance of verification), we do not have any ex ante predictions about how they will affect the truthfulness of the experts' statements or the quality of subjects' decisions. The reason we lack clear predictions for the experts' and subjects' behavior is simply that, under each one of these conditions, the conflicting-interest expert does not necessarily have an incentive to make truthful statements, in equilibrium. Specifically, the conflicting-interest expert may earn more money if he or she lies about the correct answer to the math problem. Knowing this, subjects solving the math problems may or may not trust the experts' statements.

Indeed, whether the experts (particularly the conflicting-interest expert) tell the truth in these experimental conditions and whether subjects trust the experts' statements hinges critically on their beliefs about one another. For example, in the smaller (i.e., \$1) penalty for lying condition, if the conflicting-interest expert believes that a particular math problem is easy (in the sense that most subjects will answer the problem correctly on their own), then this expert should tell the truth about the correct answer in order to avoid the $\$ 1$ penalty, as there would be little or no profit in lying. Similarly, if subjects believe that the conflicting-interest expert believes that the math problem is easy, then they should trust the experts' statements if they cannot answer the problem correctly on their own. The irony, of course, is that if the problem is easy enough, subjects do not need expert testimony to answer the problem correctly. On the other hand, if the experts believe that a particular math problem is diffcult (in the sense that most subjects will not be able to answer the problem correctly on their own), then the conflicting-interest expert may have an incentive to lie about the correct answer to the problem. Because the experts' and subjects' behavior in these experimental conditions depends on their beliefs about each other and on their beliefs about the difficulty of the math problems, we must simply observe ex post the truthfulness of the experts' statements and the quality of subjects' decisions in these conditions. That said, we suspect that as size of the penalty for lying and the chance of verification increase, both experts will be more likely to tell the truth and subjects will be more likely to trust the experts' statements and, therefore, achieve even larger improvements in their decisions. 


\section{Exchange of Reasons}

Allowing both competing experts to exchange reasons for why their statements may be correct does not alter the basic competition hypotheses that we state above. That is, even though the competing experts offer reasons for their statements and have the opportunity to go back and forth, we still predict that subjects will not improve their decisions, relative to subjects in the control group. We make this prediction because, theoretically, providing both experts with opportunities to exchange reasons does not change the cheap-talk equilibrium that exists in the basic competition condition. ${ }^{19}$ This result is true except in cases where the reason given is sufficiently clear that it allows subjects to self-verify their answer before they make a decision.

\section{Methodology}

To test our predictions, we conducted laboratory experiments at a large public university. When recruiting subjects, we posted flyers at various locations on campus, and we also sent out campus-wide emails to advertise the experiments. A total of 324 adults who were enrolled in undergraduate classes and who were of different ages, races, genders, and college majors participated.

When examining the data gleaned from these experiments, we conduct four different analyses. First, we assess the effect that each experimental condition has on the experts' propensity to make truthful statements. To this end, we estimate a random effects logistic regression in which we regress a dummy variable for whether an expert makes a truthful statement (coded 1 if an expert makes a truthful statement and 0 otherwise) on (1) a COMMON-INTEREST EXPERT dummy variable (coded 1 for common-interest experts and 0 for conflicting-interest experts), (2) a dummy variable for each experimental condition (i.e., the $\$ 15$ PENALTY variable is coded 1 for the $\$ 15$ penalty for lying condition and 0 otherwise), and (3) variables that control for the order in which subjects solve the problems and the difficulty of the

\footnotetext{
${ }^{19}$ As in the basic competition condition, subjects receive a joint signal from the experts and they are not told which expert is more likely to share common interests with them. Again, this helps us to capture subjects' fundamental uncertainty about which expert is on their side. Additionally, in the reason-giving conditions, subjects receive the experts' exchange of statements and reasons in a single transcript that is provided to them after the experts finish going back and forth. Thus, the experts' statements and reasons are provided as one joint statement.
} 
problems, as well as characteristics of the subjects. ${ }^{20}$ The omitted category in this regression is the competition condition. Thus, positive and significant coefficients in this model indicate that a particular experimental condition increases the experts' propensity to tell the truth, relative to experts in the competition condition. Random effects regressions are used throughout this article to account for the fact that the experts and subjects make multiple decisions in our experiments.

Second, we analyze the effect that each experimental condition has on the quality of subjects' decisions (measured as either the amount of money subjects earn or the accuracy of their decisions). Specifically, we estimate random effects models ${ }^{21}$ in which we regress a variable that reflects either money earned or accuracy on (1) a dummy variable for each experimental condition (coded as described above) and (2) variables that control for the order in which subjects solve the problems and the difficulty of the problems, as well as characteristics of the subjects. In an important variation of these models, we also include a Two TRUE STATEMENTS IN COMPETITION CONDITION dummy variable (coded 1 if a subject receives two true statements in the competition condition and 0 otherwise). The omitted category in these regressions is the control group. Thus, positive and significant coefficients in these models indicate that a particular experimental condition increases either the amount of money that subjects earn or the accuracy of their decisions, relative to subjects in the control group.

Third, we analyze the effect that receiving two true statements in each experimental condition has on the quality of subjects' decisions. Specifically, we estimate random effects models in which we regress a variable that reflects either money earned or accuracy on (1) a dummy variable for each additional institutional condition (coded as described above), (2) a Two TRUE STATEMENTS dummy variable (coded 1 if a subject receives two true

\footnotetext{
${ }^{20}$ Specifically, the ORDER variable captures the number of math problems used in a particular experiment, as well as the order in which they were presented to subjects. The Difriculty variable reflects the percentage of control group subjects that answer each problem correctly; thus, higher values of this variable indicate an easier problem. As for the characteristics of subjects, we control for whether they have taken a college math class, their year in school, and their SAT math score, as well as whether their college major is in a math-related discipline. We control for these subject characteristics because there were small differences in them across our various treatment groups. To save space, we do not report the results of these control variables in Tables 1-3, but they are available from the authors upon request.

${ }^{21}$ We estimate random effects GLS regressions when money earned is the dependent variable and random effects logistic regressions when accuracy is the dependent variable.
} 
statements and 0 otherwise), (3) interactions between Two TRUE STATEMENTS and the dummy variables for each additional institutional condition, and (4) variables that control for the order in which subjects solve the problems and the difficulty of the problems, as well as characteristics of the subjects. The omitted category in these regressions is the competition condition. Thus, in these models, positive and significant coefficients for the interaction terms indicate that receiving two true statements in a particular experimental condition improves subjects' decisions, relative to the competition condition. ${ }^{22}$ Note also that the coefficient for the Two TRuE STATEMENTS dummy variable reflects the effect of receiving two true statements in the competition condition.

Fourth, for each of the random effects models that we estimate, we use Wald tests to compare the coefficients for each treatment condition. These analyses allow us to test whether particular treatment conditions are significantly different from one another with respect to the extent to which they increase the experts' propensity to make truthful statements or help subjects make better decisions. For example, we assess whether the experts are significantly more likely to make truthful statements in the large (i.e., \$15) penalty for lying condition, relative to the smaller (i.e., $\$ 5$ or $\$ 1$ ) penalty for lying conditions. We also assess whether subjects make significantly better decisions when a smaller 50 percent chance of verification (without a conditional penalty) is imposed on the experts, relative to a 50 percent chance of verification with either a $\$ 1$ or $\$ 2$ conditional penalty.

\section{Results}

\section{A. The Experts' Propensity to Tell the Truth}

As shown in Table 1, many of the additional institutions that we impose increase the experts' propensity to make truthful statements, relative to experts in the basic competition condition. As predicted, the experts are significantly more likely to make truthful statements in the $\$ 15$ penalty for lying condition and in the 100 percent chance of verification plus a $\$ 1$

\footnotetext{
${ }^{22}$ Two false statements are quite rare in our data. Thus, we could not systematically analyze the effect of receiving two false statements. Additionally, because two false statements are so rare, the results of this regression are the inverse of regressions that include interactions between (1) a variable that reflects whether subjects receive two conflicting statements and (2) the dummy variables for each additional institutional condition.
} 
Table 1: In a Competition Between Two Experts, the Effect of Each Experimental Condition on the Experts' Propensity to Tell the Truth ${ }^{\mathbf{a}}$

\begin{tabular}{|c|c|}
\hline Independent Variables & $\begin{array}{c}\text { Dependent Variable }=\text { Whether an Expert } \\
\text { Tells the Truth on a Civen Problem }\end{array}$ \\
\hline Common-interest expert & $\begin{array}{c}2.856^{*} \\
(0.356)\end{array}$ \\
\hline$\$ 15$ penalty for lying & $\begin{array}{l}3.629 * \\
(1.167)\end{array}$ \\
\hline$\$ 5$ penalty for lying & $\begin{array}{r}3.550^{*} \\
(1.064)\end{array}$ \\
\hline$\$ 1$ penalty for lying & $\begin{array}{r}2.678^{*} \\
(0.766)\end{array}$ \\
\hline $100 \%$ verification & $\begin{array}{c}0.993 \\
(0.551)\end{array}$ \\
\hline $100 \%$ verification $+\$ 1$ penalty & $\begin{array}{r}4.125^{*} \\
(0.869)\end{array}$ \\
\hline $50 \%$ verification & $\begin{array}{c}0.197 \\
(0.546)\end{array}$ \\
\hline $50 \%$ verification $+\$ 1$ penalty & $\begin{array}{r}2.607^{*} \\
(0.978)\end{array}$ \\
\hline $50 \%$ verification $+\$ 2$ penalty & $\begin{array}{r}1.868^{*} \\
(0.687)\end{array}$ \\
\hline Free reasoning & $\begin{array}{l}-0.559 \\
(1.165)\end{array}$ \\
\hline Costly reasoning & $\begin{array}{l}-0.215 \\
(1.222)\end{array}$ \\
\hline Constant & $\begin{array}{l}-5.787 \\
(1.624)\end{array}$ \\
\hline $\begin{array}{l}\text { Pseudo } R^{2} \\
N\end{array}$ & $\begin{array}{c}0.340 \\
492\end{array}$ \\
\hline
\end{tabular}

${ }^{a}$ Table 1 displays the coefficients from the logistic regression that we estimated. The competition condition is the omitted category. We also estimated these results using a random effects logistic regression, which demonstrates that there is not a significant random effect. The results for the control variables are not shown in this table, nor are the confidence intervals for each coefficient. These results and confidence intervals are available from the authors on request or can be found at http://mccubbins.ucsd.edu/. Also, the variable for the 100 percent verification plus a $\$ 2$ penalty condition was dropped from this model because both experts always tell the truth in this condition.

Note: Standard errors in parentheses; ${ }^{*} p<0.05$.

penalty condition $(p<0.05) .{ }^{23}$ Specifically, Table 4 shows that the $\$ 15$ penalty for lying increases the chance that the experts make truthful state-

\footnotetext{
${ }^{23}$ The variable for the 100 percent chance of verification plus a $\$ 2$ penalty for lying condition was dropped from the regression in Table 1 because all experts make truthful statements in that condition.
} 
ments by 44 percent, and the 100 percent chance of verification plus a $\$ 1$ penalty increases the chance that the experts make truthful statements by 46 percent. Interestingly, the smaller penalty for lying conditions also significantly increase the experts' propensity to tell the truth, as do the smaller chances of verification when they are combined with conditional penalties for lying $(p<0.05)$. As shown in Table 4, each of these smaller penalties for lying and smaller chances of verification increases the chance that the experts make truthful statements by more than 34 percent. However, when the threat of verification is not combined with a conditional penalty for lying, we do not observe any increases in the experts' propensity to tell the truth. We also do not observe any increases in the experts' propensity to tell the truth in the reason-giving treatment conditions. Indeed, in the reason-giving treatment conditions, the common-interest expert always makes truthful statements, but the conflicting-interest expert always makes false statements.

When comparing the experts' propensity to tell the truth in each of these experimental conditions, several surprising findings emerge. First, there is not a significant difference in the experts' propensity to tell the truth in the $\$ 15, \$ 5$, and $\$ 1$ penalty for lying conditions $(p>0.28) .{ }^{24}$ Thus, these smaller penalties for lying are just as effective as the large $\$ 15$ penalty at inducing the experts to make truthful statements. Second, there is not a significant difference between the experts' propensity to tell the truth in the smaller $\$ 5$ penalty for lying condition versus the 100 percent chance of verification plus a $\$ 1$ penalty condition $(p=0.49)$. Thus, the smaller $\$ 5$ penalty for lying is not only as effective as the larger $\$ 15$ penalty, but it is also as effective as a 100 percent chance of verification plus a $\$ 1$ penalty for lying.

Third, there is not a significant difference between a 50 percent chance of verification (without a conditional penalty) and a 100 percent chance of verification (without a conditional penalty) $(p=0.09)$. Thus, increasing the chance of verification without adding a conditional penalty does not significantly increase the experts' propensity to tell the truth. Fourth, as expected, when a conditional penalty for lying is added to the threat of verification, the experts are significantly more likely to tell the truth than when there is not

\footnotetext{
${ }^{24}$ The $p$ value that we report here is true for each pair-wise comparison between the three different penalty for lying conditions. More accurately, when the experts' propensity to tell the truth in the $\$ 15$ penalty for lying condition is compared to the experts' propensity to tell the truth in the $\$ 5$ penalty for lying condition, $p$ is equal to 0.95 . When the $\$ 15$ penalty for lying condition is compared to the $\$ 1$ penalty for lying condition, $p$ is equal to 0.43 . When the $\$ 5$ penalty for lying condition is compared to the $\$ 1$ penalty for lying condition, $p$ is equal to 0.29 .
} 
a conditional penalty $(p<0.01) \cdot{ }^{25}$ Fifth, there is not a significant difference in the experts' propensity to tell the truth in the free reasoning versus costly reasoning conditions $(p=0.82)$, nor is there a difference in the experts' propensity to tell the truth when the 50 percent chance of verification is combined with a $\$ 1$ versus a $\$ 2$ conditional penalty $(p=0.34)$.

\section{B. Improvements in Subjects'Decisions}

Our analysis of the quality of subjects' decisions suggests important lessons about the effects that competition (with and without additional institutions) has on subjects' ability to improve their decisions. As shown in Table 2 (and as predicted), competition, by itself, tends not to help subjects improve their decisions, relative to subjects in the control group. However, the additional institutions, as well as the reason-giving conditions, help subjects achieve large improvements in their decisions, relative to subjects in the control group. Specifically, subjects make significantly better decisions in the large $\$ 15$ penalty for lying condition and in the 100 percent chance of verification (with or without a $\$ 1$ or $\$ 2$ penalty) conditions $(p<0.05){ }^{26}$

\footnotetext{
${ }^{25}$ Specifically, when the experts' propensity to tell the truth in the 50 percent chance of verification (without a penalty) condition is compared to the experts' propensity to tell the truth in the 50 percent chance of verification plus a $\$ 1$ penalty condition, $p$ is equal to 0.009 . When the 50 percent chance of verification (without a penalty) condition is compared to the 50 percent chance of verification plus a $\$ 2$ penalty condition, $p$ is also equal to 0.009 . When the 100 percent chance of verification (without a penalty) condition is compared to the 100 percent chance of verification plus a $\$ 1$ penalty condition, $p$ is less than 0.001 .
}

${ }^{26}$ Interestingly, subjects do not answer every math problem correctly in the 100 percent chance of verification conditions. Although one might be concerned that subjects are confused about the procedures used in our experiments, we are confident that this result does not stem from subjects' confusion. The reason for this is that, after reading the instructions for a given treatment condition, the experimenter gives subjects a short quiz that asks them about their own incentives, the incentives of the experts, and the way that a particular treatment works. For example, on the quiz for the 100 percent chance of verification condition, subjects are asked what percentage of the time the experimenter will verify both experts' statements and announce the correct answer to the math problem (the correct answer to this question is " 100 percent"). To motivate performance on the quiz, the experimenter tells subjects that they earn 25 cents for each quiz question they answer correctly. After subjects finish taking the quiz, the experimenter corrects subjects' quizzes in front of them, explains any wrong answers to them, and pays them the money they earned for their performance on the quiz. Subjects, by and large, answer all the quiz questions correctly. Indeed, there were very few instances where the experimenter had to explain to subjects why the answer they chose was wrong. The experimenter also conducts informal post-experiment conversations 
As shown in Table 4 , the $\$ 15$ penalty for lying increases the chance that subjects make a correct choice by 56 percent, and each of the 100 percent chance of verification conditions increases the chance that subjects make a correct choice by more than 53 percent. Interestingly, the smaller penalties for lying also help subjects achieve significant improvements in their decisions, as does the smaller 50 percent chance of verification (with or without a $\$ 1$ or $\$ 2$ conditional penalty) $(p<0.05) .{ }^{27}$ We also observe significant improvements in subjects' decisions when the competing experts exchange

with subjects, asking them about their understanding of the experts' incentives, as well as their own incentives and the way that verification worked. In these conversations, no subjects expressed confusion about the treatment condition. Thus, we are confident that all subjects understood the experts' incentives, their own incentives, and the procedures used in each treatment condition. What the informal post-experiment conversations with subjects reveal, however, is that subjects who behave anomalously in the 100 percent chance of verification condition (i.e., either lie as the expert or not trust the experts' statements) are either bored, make a mistake, or want to see what happens if they do not behave as expected. Unfortunately, boredom, making a mistake, and wanting to see how the experimenter reacts to anomalous behavior are factors that play a role in nearly all laboratory experiments. Indeed, we have replicated our 100 percent chance of verification treatment conditions in other, slightly different experiments, and we never observe behavior that is perfectly consistent with our predictions. For example, Boudreau (2006) shows that when a 100 percent chance of verification plus a $\$ 2$ penalty for lying is imposed on one expert, subjects answer only 83 percent of the math problems correctly (not the full 100 percent that we would expect, given that the expert's statement is always verified by the experimenter). Perhaps more astonishingly, Lupia and McCubbins (1998) pay subjects to predict that the outcome of an unseen coin toss was heads (regardless of whether that prediction was correct), and they find that subjects predict heads only 86 percent of the time (which is significantly different than the expected 100 percent).

${ }^{27}$ As shown in Table 2, the smaller 50 percent chance of verification (without a conditional penalty) helps subjects achieve a significant improvement in the accuracy of their decisions (relative to subjects in the control group; $p<0.05$ ), but not in the amount of money they earn. Also, subjects in this additional institutional condition are not able to improve their decisions, relative to subjects in the basic competition condition $(p>0.22)$. Specifically, when the 50 percent chance of verification (without a penalty) condition is compared to the basic competition condition in the money earned models, $p$ is equal to 0.23 when the Two TRUE STATEMENTS IN COMPETITION CONDITION variable is not included in the model and is equal to 0.66 when the TWO TRUE STATEMENTS IN COMPETITION CONDITION variable is included in the model. When the 50 percent chance of verification (without a penalty) condition is compared to the basic competition condition in the accuracy models, $p$ is equal to 0.66 when the TWO TRUE STATEMENTS IN COMPETITION CONDITION variable is not included in the model and is equal to 0.29 when the Two TRUE STATEMENTS IN COMPETITION CONDITION variable is included in the model. 
Table 2: The Effect of Each Experimental Condition on the Amount of Money Subjects Earn and the Accuracy of Subjects' Decisions ${ }^{\mathrm{a}}$

\begin{tabular}{|c|c|c|c|c|}
\hline \multirow{2}{*}{$\frac{\text { Independent Variables }}{\text { Competition }}$} & \multicolumn{2}{|c|}{$\begin{array}{c}\text { Money Eamed Models } \\
\text { (Dependent Variable }=\text { Amount of } \\
\text { Money Subjects Earn on } \\
\text { a Given Problem) }\end{array}$} & \multicolumn{2}{|c|}{$\begin{array}{c}\text { Accuracy Models } \\
\text { (Dependent Variable }=\text { Whether } \\
\text { Subjects Answer } a \text { Given } \\
\text { Problem Correctly) }\end{array}$} \\
\hline & $\begin{array}{c}0.056 \\
(0.029)\end{array}$ & $\begin{array}{c}-0.015 \\
(0.032)\end{array}$ & $\begin{array}{l}1.106^{*} \\
(0.274)\end{array}$ & $\begin{array}{c}0.556 \\
(0.291)\end{array}$ \\
\hline $\begin{array}{l}\text { The effect of receiving two } \\
\text { true statements in the } \\
\text { competition condition }\end{array}$ & - & $\begin{array}{r}0.250^{*} \\
(0.050)\end{array}$ & - & $\begin{array}{r}2.596^{*} \\
(0.571)\end{array}$ \\
\hline$\$ 15$ penalty for lying & $\begin{array}{c}0.290^{*} \\
(0.033)\end{array}$ & $\begin{array}{c}0.287^{*} \\
(0.032)\end{array}$ & $\begin{array}{r}3.535^{*} \\
(0.399)\end{array}$ & $\begin{array}{c}3.540^{*} \\
(0.397)\end{array}$ \\
\hline$\$ 5$ penalty for lying & $\begin{array}{c}0.249^{*} \\
(0.032)\end{array}$ & $\begin{array}{c}0.248^{*} \\
(0.032)\end{array}$ & $\begin{array}{c}2.577^{*} \\
(0.353)\end{array}$ & $\begin{array}{c}2.594^{*} \\
(0.351)\end{array}$ \\
\hline$\$ 1$ penalty for lying & $\begin{array}{r}0.230^{*} \\
(0.032)\end{array}$ & $\begin{array}{r}0.229 * \\
(0.031)\end{array}$ & $\begin{array}{r}2.683^{*} \\
(0.367)\end{array}$ & $\begin{array}{r}2.712^{*} \\
(0.366)\end{array}$ \\
\hline $100 \%$ verification & $\begin{array}{c}0.243^{*} \\
(0.034)\end{array}$ & $\begin{array}{c}0.240^{*} \\
(0.034)\end{array}$ & $\begin{array}{c}3.160^{*} \\
(0.406)\end{array}$ & $\begin{array}{c}3.168^{*} \\
(0.404)\end{array}$ \\
\hline $\begin{array}{l}100 \% \text { verification + } \\
\$ 1 \text { penalty }\end{array}$ & $\begin{array}{c}0.300^{*} \\
(0.029)\end{array}$ & $\begin{array}{c}0.297^{*} \\
(0.028)\end{array}$ & $\begin{array}{c}3.981^{*} \\
(0.407)\end{array}$ & $\begin{array}{c}3.976^{*} \\
(0.404)\end{array}$ \\
\hline $\begin{array}{l}100 \% \text { verification }+ \\
\$ 2 \text { penalty }\end{array}$ & $\begin{array}{r}0.344^{*} \\
(0.032)\end{array}$ & $\begin{array}{c}0.342^{*} \\
(0.031)\end{array}$ & $\begin{array}{r}5.976^{*} \\
(1.037)\end{array}$ & $\begin{array}{r}5.959 * \\
(1.035)\end{array}$ \\
\hline $50 \%$ verification & $\begin{array}{c}0.007 \\
(0.037)\end{array}$ & $\begin{array}{c}0.003 \\
(0.037)\end{array}$ & $\begin{array}{r}0.950^{*} \\
(0.341)\end{array}$ & $\begin{array}{c}0.947^{*} \\
(0.338)\end{array}$ \\
\hline $\begin{array}{l}50 \% \text { verification }+ \\
\$ 1 \text { penalty }\end{array}$ & $\begin{array}{c}0.190^{*} \\
(0.030)\end{array}$ & $\begin{array}{c}0.188^{*} \\
(0.030)\end{array}$ & $\begin{array}{c}2.183^{*} \\
(0.313)\end{array}$ & $\begin{array}{r}2.170^{*} \\
(0.310)\end{array}$ \\
\hline $\begin{array}{l}50 \% \text { verification }+ \\
\$ 2 \text { penalty }\end{array}$ & $\begin{array}{c}0.128^{*} \\
(0.035)\end{array}$ & $\begin{array}{c}0.127^{*} \\
(0.035)\end{array}$ & $\begin{array}{c}1.779^{*} \\
(0.346)\end{array}$ & $\begin{array}{r}1.805^{*} \\
(0.344)\end{array}$ \\
\hline Free reasoning & $\begin{array}{c}0.129^{*} \\
(0.039)\end{array}$ & $\begin{array}{c}0.125^{*} \\
(0.039)\end{array}$ & $\begin{array}{l}2.046^{*} \\
(0.373)\end{array}$ & $\begin{array}{r}2.060^{*} \\
(0.372)\end{array}$ \\
\hline Costly reasoning & $\begin{array}{c}0.151^{*} \\
(0.038)\end{array}$ & $\begin{array}{c}0.148^{*} \\
(0.037)\end{array}$ & $\begin{array}{c}1.965^{*} \\
(0.355)\end{array}$ & $\begin{array}{c}1.966^{*} \\
(0.352)\end{array}$ \\
\hline Constant & $\begin{array}{l}-0.348 \\
(0.073)\end{array}$ & $\begin{array}{l}-0.325 \\
(0.071)\end{array}$ & $\begin{array}{l}-6.033 \\
(0.813)\end{array}$ & $\begin{array}{l}-5.850 \\
(0.804)\end{array}$ \\
\hline Rho & 0.021 & 0.014 & 0.092 & 0.084 \\
\hline$R^{2}$ & 0.264 & 0.271 & - & - \\
\hline Log likelihood & - & - & -1080.87 & -1067.53 \\
\hline$N$ & 2,450 & 2,450 & 2,450 & 2,450 \\
\hline Groups & 225 & 225 & 225 & 225 \\
\hline
\end{tabular}

Table 2 displays the coefficients from the regressions that we estimated. Specifically, the money earned models were estimated using random effects GLS regressions, and the accuracy models were estimated using random effects logistic regressions. The control group is the omitted category in these regressions. Note that the results for the control variables are not shown in this table, nor are the confidence intervals for each coefficient. These results and confidence intervals are available from the authors upon request.

NoTE: Standard errors in parentheses; $* p<0.05$. 
reasons with one another (either for free or with a small cost imposed on them) $(p<0.05) .^{28}$

When comparing the improvements in subjects' decisions in each experimental condition, several interesting findings emerge. First, there tends not to be a significant difference in the extent to which subjects improve their decisions in the $\$ 15, \$ 5$, and $\$ 1$ penalty for lying conditions $(p>0.06) .{ }^{29}$ Indeed, Table 4 shows that the smaller $\$ 5$ penalty for lying increases the chance that subjects make a correct choice by 50 percent, and the $\$ 1$ penalty for lying increases the chance that subjects make a correct choice by 51 percent. Thus, these smaller penalties for lying can be just as effective as the large $\$ 15$ penalty at improving subjects' decisions. ${ }^{30}$ Second, as expected, subjects tend to achieve significantly greater improvements in

\footnotetext{
${ }^{28} \mathrm{McCubbins}$ and Rodriguez (2006) conduct related experiments in which subjects have the opportunity to receive information from their peers in a deliberative setting. In one variation of their experiments, subjects have the opportunity to send and receive reasons (either for free or with a small cost) for why a particular answer may be correct. When the exchange of reasons is free, there is a significant increase in social welfare and the accuracy of subjects' decisions. When there is a cost associated with exchanging reasons, however, social welfare and accuracy significantly decrease. Indeed, subjects in the costly reasoning conditions earn less money and answer fewer problems correctly than subjects in a control setting who cannot communicate with one another. These results demonstrate that once there is a cost associated with receiving information, people tend not to receive it and make worse decisions as a consequence.
}

${ }^{20}$ When the $\$ 15$ penalty for lying condition is compared to the $\$ 5$ penalty for lying condition in the money earned models, $p$ is equal to 0.34 when the TWO TRUE STATEMENTS IN COMPETITION CONDITION variable is not included in the model and is equal to 0.36 when the Two TruE STATEMENTS IN COMPETITION CONDITION variable is included in the model. When the $\$ 15$ penalty for lying condition is compared to the $\$ 1$ penalty for lying condition in the money earned models, $p$ is equal to 0.14 when the TWO TRUE STATEMENTS IN COMPETITION CONDITION variable is not included in the model and is equal to 0.15 when the TWO TRUE STATEMENTS IN COMPETITION CONDITION variable is included in the model. When the $\$ 5$ penalty for lying condition is compared to the $\$ 1$ penalty for lying condition in the money earned models, $p$ is equal to 0.64 when the Two TRUE STATEMENTS IN COMPETITION CONDITION variable is not included in the model and is equal to 0.63 when the Two TRUE STATEMENTS IN COMPETITION CONDITION variable is included in the model. In both accuracy models, when the $\$ 15$ penalty for lying condition is compared to the $\$ 1$ penalty for lying condition, $p$ is equal to 0.07 . When the $\$ 5$ penalty for lying condition is compared to the $\$ 1$ penalty for lying condition in the accuracy models, $p$ is equal to 0.81 when the TWO TRUE STATEMENTS IN COMPETITION CONDITION variable is not included in the model and is equal to 0.78 when the Two TRUe STATEMENTS IN COMPETITION CONDITION variable is included in the model.

${ }^{30}$ The one exception to this statement occurs when we use accuracy as our dependent variable. In the accuracy models, the large $\$ 15$ penalty for lying induces a significantly larger improvement than does the smaller $\$ 5$ penalty for lying ( $p<0.05$ in both models). 
their decisions when the threat of verification is combined with a conditional penalty versus when it is not $(p<0.05) .{ }^{31}$ Third, all the additional institutional conditions (except for the 50 percent chance of verification without a conditional penalty) help subjects achieve significant improvements in their decisions, relative to subjects in the basic competition condition $(p<0.01$ for all comparisons between the basic competition condition and the additional institutional conditions).$^{32}$ Fourth, there is not a significant difference in the extent to which subjects improve their decisions in the free reasoning versus costly reasoning conditions $(p>0.62) .{ }^{33}$ That said, the experts' exchange of reasons does lead to significant improvements in subjects' decisions, relative to subjects' decisions in the basic competition condition $(p<0.05$ for all comparisons between the basic competition condition and the free and costly reasoning conditions) ${ }^{34}$

\footnotetext{
${ }^{31}$ In all the money earned and accuracy models, $p$ is less than 0.05 when the 50 percent chance of verification (without a penalty) condition is compared to the 50 percent chance of verification plus a $\$ 1$ penalty condition and to the 50 percent chance of verification plus a $\$ 2$ penalty for lying condition. In all the money earned and accuracy models, $p$ is less than 0.05 when the 100 percent chance of verification (without a penalty) condition is compared to the 100 percent chance of verification plus a $\$ 2$ penalty condition. The one exception to the statement we make in the text occurs when we compare the coefficients for the 100 percent chance of verification (without a penalty) condition and the 100 percent chance of verification plus a $\$ 1$ penalty condition. Specifically, there is not a significant difference between the improvements subjects achieve in these two conditions $(p=0.13$ in the money earned models and $p=0.09$ in the accuracy models).
}

${ }^{32}$ Results for the 50 percent chance of verification plus a $\$ 2$ penalty condition are mixed. Specifically, when the Two TRUE STATEMENTS IN COMPETITION CONDITION variable is not included in the money earned and accuracy models, then the coefficient for the 50 percent chance of verification plus a $\$ 2$ penalty condition is not significantly greater than the coefficient for the basic competition condition $(p=0.07$ in the money earned model and $p=0.06$ in the accuracy model). When the TWO TRUE STATEMENTS IN COMPETITION CONDITION variable is included in the money earned and accuracy models, then the coefficient for the 50 percent chance of verification plus a $\$ 2$ penalty condition is significantly greater than the coefficient for the basic competition condition ( $p<0.001$ for both models).

${ }^{33}$ In the money earned models, $p$ is equal to 0.63 when the coefficient for the free reasoning condition is compared to the coefficient for the costly reasoning condition. In the accuracy models, $p$ is equal to 0.8 when the free reasoning condition is compared to the costly reasoning condition.

${ }^{34}$ When the TWO TRUE STATEMENTS IN COMPETITION CONDITION variable is not included in the money earned model, the $p$ value for the comparison between the free reasoning condition and the competition condition is 0.08 . 


\section{The Same Statement Heuristic: Two of the Same Statements = Two True Statements}

Thus far, our results have been remarkably consistent with our predictions. However, when we break down our aggregate results to examine the effect of receiving two true statements in each experimental condition, we find interesting (and surprising) results. As seen in Tables 2 and 3, it appears that the effectiveness of basic competition (without additional institutions or the exchange of reasons) hinges critically on the truthfulness of the experts' statements. Specifically, our results show that, contrary to cheaptalk models, when subjects receive two true statements from the experts in the basic competition condition, they are able to achieve significant improvements in their decisions $(p<0.05)$. Indeed, not only do subjects earn more money when they receive two true statements in the basic competition condition, but, as shown in Table 4 , they are also 37 percent more likely to make a correct choice. Thus, subjects do not appear to ignore the experts' statements in the competition condition. Rather, they appear to rely on a simple (and effective) rule of thumb: "Upon receiving two of the same statements (i.e., either "a, a" or " $b, b$ ") in the competition condition, assume that both experts are telling the truth." Interestingly, this rule of thumb is quite helpful, as the assumption that two of the same statements equal two true statements largely turns out to be correct. ${ }^{35}$ That is, it is very rare for both experts to make false statements in the competition condition (it occurred only twice).

When subjects receive two true statements in the additional institutional conditions, we observe another interesting result: namely, that receiving two true statements helps subjects improve their decisions consistently only when the additional institution gives both experts a dominant strategy to tell the truth. Stated differently, only when the additional institution makes both experts trustworthy do subjects consistently benefit from receiving two true statements. For example, as shown in Tables 3 and 4, subjects achieve significant improvements in their decisions when they receive two true statements in the $\$ 15$ penalty for lying condition $(p<0.05)$. Specifically,

\footnotetext{
${ }^{35}$ In future work, we explore potential explanations for why subjects make the out-of-equilibrium assumption that two of the same statements equal two true statements in the basic competition condition. We suspect that this assumption stems from subjects' beliefs about others-beliefs that subjects develop based on their experiences in the real world and that they then bring with them to the experiment. For a discussion of how subjects bring their own expectations and beliefs to experimental settings, see Sher and McKenzie (2008).
} 
Table 3: The Effect that Receiving Two True Statements from the Experts in Each Experimental Condition Has on the Amount of Money Subjects Earn and the Accuracy of Subjects' Decisions ${ }^{a}$

\begin{tabular}{|c|c|c|}
\hline Independent Variables & $\begin{array}{c}\text { Money Earned Model } \\
\text { (Dependent Variable = Amount } \\
\text { of Money Subjects Earn } \\
\text { on a Given Problem) }\end{array}$ & $\begin{array}{c}\text { Accuracy Model } \\
\text { (Dependent Variable }=\text { Whether } \\
\text { Subjects Answer a Given } \\
\text { Problem Correctly) }\end{array}$ \\
\hline $\begin{array}{l}\text { Two true statements (in } \\
\text { competition condition) }\end{array}$ & $\begin{array}{r}0.251^{*} \\
(0.047)\end{array}$ & $\begin{array}{r}2.324^{*} \\
(0.551)\end{array}$ \\
\hline$\$ 15$ penalty for lying & $\begin{array}{l}-0.182 * \\
(0.087)\end{array}$ & $\begin{array}{c}-1.329 \\
(1.109)\end{array}$ \\
\hline$\$ 5$ penalty for lying & $\begin{array}{c}0.012 \\
(0.077)\end{array}$ & $\begin{array}{l}-0.217 \\
(0.689)\end{array}$ \\
\hline$\$ 1$ penalty for lying & $\begin{array}{c}0.092 \\
(0.054)\end{array}$ & $\begin{array}{c}0.262 \\
(0.454)\end{array}$ \\
\hline $50 \%$ verification & $\begin{aligned}-0.252^{*} \\
(0.053)\end{aligned}$ & $\begin{array}{l}-0.533 \\
(0.441)\end{array}$ \\
\hline $\begin{array}{l}50 \% \text { verification }+ \\
\$ 1 \text { penalty }\end{array}$ & $\begin{array}{c}0.046 \\
(0.079)\end{array}$ & $\begin{array}{l}-0.215 \\
(0.733)\end{array}$ \\
\hline $\begin{array}{l}50 \% \text { verification }+ \\
\$ 2 \text { penalty }\end{array}$ & $\begin{array}{l}-0.370^{*} \\
(0.082)\end{array}$ & $\begin{array}{l}-1.201 \\
(0.831)\end{array}$ \\
\hline Two true $* \$ 15$ penalty & $\begin{array}{r}0.257^{*} \\
(0.099)\end{array}$ & $\begin{array}{r}2.930^{*} \\
(1.360)\end{array}$ \\
\hline Two true $* \$ 5$ penalty & $\begin{array}{c}-0.019 \\
(0.082)\end{array}$ & $\begin{array}{c}0.540 \\
(0.879)\end{array}$ \\
\hline Two true $* \$ 1$ penalty & $\begin{array}{l}-0.061 \\
(0.073)\end{array}$ & $\begin{array}{c}0.782 \\
(0.906)\end{array}$ \\
\hline Two true $* 50 \%$ verification & $\begin{array}{r}0.261^{*} \\
(0.078)\end{array}$ & $\begin{array}{c}0.236 \\
(0.929)\end{array}$ \\
\hline $\begin{array}{l}\text { Two true } * 50 \% \text { verification } \\
+\$ 1 \text { penalty }\end{array}$ & $\begin{array}{l}-0.131 \\
(0.082)\end{array}$ & $\begin{array}{l}-0.558 \\
(0.806)\end{array}$ \\
\hline $\begin{array}{l}\text { Two true * } 50 \% \text { verification } \\
+\$ 2 \text { penalty }\end{array}$ & $\begin{array}{r}0.320^{*} \\
(0.095)\end{array}$ & $\begin{array}{c}0.348 \\
(1.018)\end{array}$ \\
\hline Constant & $\begin{array}{l}-0.191 \\
(0.102)\end{array}$ & $\begin{array}{l}-3.884 \\
(1.121)\end{array}$ \\
\hline Rho & 0.012 & 0.036 \\
\hline$R^{2}$ & 0.320 & - \\
\hline Log likelihood & - & -290.73 \\
\hline$N$ & 779 & 779 \\
\hline Groups & 151 & 151 \\
\hline
\end{tabular}

a Table 3 displays the coefficients from the regressions that we estimated. Specifically, the money earned model was estimated using a random effects GLS regression, and the accuracy model was estimated using a random effects logistic regression. The competition condition is the omitted category in these regressions. Note that the results for the control variables are not shown in this table, nor are the confidence intervals for each coefficient. These results and confidence intervals are available from the authors upon request.

NoTE: Standard errors in parentheses; ${ }^{*} p<0.05$ 
Table 4: Changes in the Probability that the Experts Tell the Truth and that Subjects Answer Correctly in Each Experimental Conditiona

\begin{tabular}{|c|c|c|c|}
\hline Experimental Condition & $\begin{array}{c}\text { Change in Probability } \\
\text { of Experts Telling } \\
\text { the Truth }\end{array}$ & $\begin{array}{l}\text { Change in } \\
\text { Probability of a } \\
\text { Correct Answer }\end{array}$ & $\begin{array}{c}\text { Change in Probability of a } \\
\text { Correct Answer When Receiving } \\
\text { Two True Statements }\end{array}$ \\
\hline Competition & - & $\begin{array}{c}0.14 \\
(-0.003,0.277)\end{array}$ & $\begin{array}{c}\mathbf{0 . 3 7} \\
(0.240,0.509)\end{array}$ \\
\hline$\$ 15$ penalty for lying & $\begin{array}{c}\mathbf{0 . 4 4} \\
(0.180,0.697)\end{array}$ & $\begin{array}{c}\mathbf{0 . 5 6} \\
(0.495,0.630)\end{array}$ & $\begin{array}{c}0.41 \\
(0.263,0.550)\end{array}$ \\
\hline$\$ 5$ penalty for lying & $\begin{array}{c}\mathbf{0 . 4 5} \\
(0.168,0.712)\end{array}$ & $\begin{array}{c}\mathbf{0 . 5 0} \\
(0.419,0.586)\end{array}$ & $\begin{array}{c}0.13 \\
(-0.245,0.499)\end{array}$ \\
\hline$\$ 1$ penalty for lying & $\begin{array}{c}\mathbf{0 . 4 1} \\
(0.151,0.673)\end{array}$ & $\begin{array}{c}\mathbf{0 . 5 1} \\
(0.429,0.596)\end{array}$ & $\begin{array}{c}0.18 \\
(-0.172,0.526)\end{array}$ \\
\hline $100 \%$ verification & $\begin{array}{c}0.22 \\
(-0.008,0.469)\end{array}$ & $\begin{array}{c}0.54 \\
(0.469,0.620)\end{array}$ & - \\
\hline $\begin{array}{l}100 \% \text { verification }+ \\
\$ 1 \text { penalty }\end{array}$ & $\begin{array}{c}\mathbf{0 . 4 6} \\
(0.216,0.718)\end{array}$ & $\begin{array}{c}\mathbf{0 . 5 8} \\
(0.515,0.639)\end{array}$ & - \\
\hline $\begin{array}{l}100 \% \text { verification }+ \\
\$ 2 \text { penalty }\end{array}$ & - & $\begin{array}{c}\mathbf{0 . 6 0} \\
(0.543,0.659)\end{array}$ & - \\
\hline $50 \%$ verification & $\begin{array}{c}0.05 \\
(-0.209,0.291)\end{array}$ & $\begin{array}{c}\mathbf{0 . 2 3} \\
(0.076,0.388)\end{array}$ & $\begin{array}{c}0.06 \\
(-0.375,0.490)\end{array}$ \\
\hline $\begin{array}{l}50 \% \text { verification }+ \\
\$ 1 \text { penalty }\end{array}$ & $\begin{array}{c}\text { 0.41 } \\
(0.094,0.694)\end{array}$ & $\begin{array}{c}\mathbf{0 . 4 6} \\
(0.364,0.548)\end{array}$ & $\begin{array}{c}-0.14 \\
(-0.521,0.244)\end{array}$ \\
\hline $\begin{array}{l}50 \% \text { verification + } \\
\$ 2 \text { penalty }\end{array}$ & $\begin{array}{c}\mathbf{0 . 3 5} \\
(0.097,0.608)\end{array}$ & $\begin{array}{c}\mathbf{0 . 4 0} \\
(0.286,0.521)\end{array}$ & $\begin{array}{c}0.08 \\
(-0.377,0.545)\end{array}$ \\
\hline Free reasoning & $\begin{array}{c}-0.11 \\
(-0.536,0.360)\end{array}$ & $\begin{array}{c}\mathbf{0 . 4 4} \\
(0.328,0.555)\end{array}$ & - \\
\hline Costly reasoning & $\begin{array}{c}-0.05 \\
(-0.525,0.426)\end{array}$ & $\begin{array}{c}\mathbf{0 . 4 3} \\
(0.316,0.541)\end{array}$ & - \\
\hline
\end{tabular}

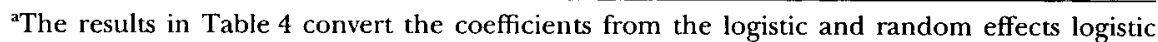
regressions reported in Tables 1, 2, and 3 to probabilities. These results reflect first differences with all other variables held constant at their median or mean values (King et al., 2000; Tomz et al., 2003).

NoTE: Confidence intervals in parentheses; boldface indicates that the $95 \%$ confidence interval does not contain zero, signifying statistical significance.

receiving two true statements in the $\$ 15$ penalty for lying condition increases the chance that subjects make a correct choice by $\mathbf{4 1}$ percent. However, when the penalty for lying is smaller (and, thus, does not ensure that both experts have a dominant strategy to tell the truth), subjects do not benefit from receiving two true statements in those conditions. Similarly, subjects in the 50 percent chance of verification plus a $\$ 1$ penalty condition do not benefit from receiving two true statements. In the other 50 percent chance of verification conditions (i.e., without a conditional penalty or with a $\$ 2$ conditional penalty), receiving two true statements helps subjects improve 
the amount of money they earn $(p<0.05)$, but not the accuracy of their decisions. ${ }^{36}$

When comparing the improvements that receiving two true statements induces in each experimental condition, several counterintuitive findings emerge. First, receiving two true statements in the competition condition induces as much of an improvement as receiving two true statements in the $\$ 15$ penalty for lying condition $(p>0.71) .{ }^{37}$ This result suggests the power of subjects' apparent assumption that two of the same statements equal two true statements in the competition condition. Indeed, that assumption enables them to achieve as large an improvement in their decisions as subjects who receive two true statements in the $\$ 15$ penalty for lying condition-a condition in which (unlike the basic competition condition) it is common knowledge that both experts have a dominant strategy to tell the truth. ${ }^{38}$

Further, not only do subjects in the smaller penalty for lying conditions not improve their decisions when they receive two true statements, but the

\footnotetext{
${ }^{36}$ The 100 percent chance of verification conditions are not included in the analysis in Table 3 because subjects always receive two true statements in these conditions. Similarly, the reasongiving conditions are not included in this analysis because subjects always receive two conflicting statements in these conditions.
}

${ }^{37}$ Specifically, $p$ is equal to 0.96 when we compare these coefficients in the money earned model, and $p$ is equal to 0.72 when we compare these coefficients in the accuracy model.

\begin{abstract}
${ }^{38}$ Receiving two true statements in the competition condition also induces as much (or more) of an improvement in subjects' decisions as do the reason-giving conditions and nearly all the additional institutional conditions. As shown in Table 2, the improvements we observe when subjects receive two true statements in the competition condition are no different from the improvements we observe in the smaller $\$ 5$ penalty for lying condition $(p>0.97)$, the smaller $\$ 1$ penalty for lying condition ( $p>0.71)$, the 100 percent chance of verification (without a penalty for lying) condition $(p>0.40)$, the costly reasoning condition $(p>0.1)$, and the 50 percent chance of verification plus a $\$ 1$ penalty condition $(p>0.28)$. Interestingly, the improvements we observe when subjects receive two true statements in the competition condition are larger than the improvements we observe in the 50 percent chance of verification (without a penalty) condition $(p<0.05)$, the 50 percent chance of verification plus a $\$ 2$ penalty condition $(p<0.05$ when money earned is the dependent variable), and the free reasoning condition $(p=0.05$ when money earned is the dependent variable). Results for the 100 percent chance of verification (with a $\$ 1$ or $\$ 2$ penalty) conditions also vary depending on whether we use money earned or accuracy as the dependent variable. When money earned is the dependent variable, there is no difference between the improvements subjects achieve when they receive two true statements in the competition condition and their improvements in the 100 percent chance of verification (with a $\$ 1$ or $\$ 2$ penalty) conditions $(p>0.12)$. When accuracy is the dependent variable, the 100 percent chance of verification (with a $\$ 1$ or $\$ 2$ penalty) conditions induce significantly larger improvements in subjects' decisions than does receiving two true statements in the competition condition ( $p<0.05$ for both comparisons).
\end{abstract}


effect of receiving two true statements in these conditions is significantly smaller than the effect of receiving two true statements in the competition condition-at least when money earned is the measure of the quality of subjects' decisions $(p<0.05) .{ }^{39}$ This result is particularly surprising because it suggests that subjects in the smaller penalty for lying conditions may not have assumed that two of the same statements equal two true statements. If they had, subjects likely would have achieved significant improvements in their decisions, as the experts in the smaller penalty for lying conditions never made two false statements to subjects. Nonetheless, this result may suggest an important lesson about how subjects perceive institutions and how additional institutions may cause them to alter their assumptions about the individuals whose statements they receive.

\section{Conclusion}

In this article, we discussed laboratory experiments that analyze a core feature of many legal, political, and economic contexts: competition between experts. Our results suggest that competition between experts, by itself, induces enough truth telling to allow subjects to improve their decisions. However, these improvements are driven by those instances in which both competing experts make truthful statements to subjects. Rather than viewing the experts' statements as cheap talk (as we expected), subjects appear to rely on a rule of thumb that helps them improve their decisions even though the experts do not both have an incentive to be truthful. Specifically, subjects appear to assume that both experts are telling the truth when they both make the same statements in the competition condition. This assumption largely turns out to be correct and, thus, it helps subjects improve their decisions.

Further, when competition is coupled with additional institutions (institutions that are common in many legal and political contexts), the

\footnotetext{
${ }^{39}$ In the money earned model, $p$ is less than 0.05 when we compare (1) the effect of receiving two true statements in the competition condition with the effect of receiving two true statements in the $\$ 5$ penalty for lying condition and (2) when we compare the effect of receiving two true statements in the competition condition with the effect of receiving two true statements in the $\$ 1$ penalty for lying condition. In the accuracy model, $p$ is equal to 0.17 when we compare the effect of receiving two true statements in the competition condition with the effect of receiving two true statements in the $\$ 5$ penalty for lying condition. Also in the accuracy model, $p$ is equal to 0.24 when we compare the effect of receiving two true statements in the competition condition with the effect of receiving two true statements in the $\$ 1$ penalty for lying condition.
} 
experts' propensity to tell the truth increases, and subjects achieve even larger improvements in their decisions. Specifically, when both experts face a penalty for lying (which they typically face in courtroom settings), both experts make truthful statements more frequently, and subjects make significantly better decisions (relative to both the control group and subjects in the competition condition). Interestingly, we find that smaller penalties for lying can be just as effective as large ones at increasing the experts' propensity to tell the truth and helping subjects improve their decisions. As for the effects of verification, we find that adding a conditional penalty for lying to the threat of verification dramatically increases the extent to which verification induces the experts to make truthful statements and helps subjects improve their decisions. Indeed, only when a 50 percent chance of verification is combined with a $\$ 1$ or $\$ 2$ conditional penalty are the experts significantly more likely to make truthful statements and the subjects consistently able to improve their decisions. Additionally, when we examine the effect that receiving two true statements in each institutional condition has on subjects' decisions, we find that only when the additional institution makes both experts trustworthy do subjects consistently benefit from receiving two true statements.

In our reason-giving experiments, we find that the back and forth between competing experts can improve subjects' decisions, even though it does not increase the experts' propensity to tell the truth. Indeed, in our reason-giving treatments, both experts always make conflicting statements about the correct answer to the math problem. Despite these conflicting statements, the experts' exchange of reasons allows subjects to improve their decisions, relative to subjects in the competition condition and in the control group. In this way, it appears that subjects are able to learn from the competing experts' exchange of testimony, as well.

As for the implications that these findings have for debates about our adversarial legal system, they suggest that, contrary to critics of our adversarial system, competition between experts, by itself, induces truth telling and improves decision making. Further, the additional institutions that exist in courtroom settings (as well as the back and forth that typically occurs between witnesses and lawyers during trials) enhance the positive effects of competition and bring about even more truth telling and larger improvements in decision making. These results are particularly encouraging, as competition between experts in real-world legal settings does not occur in a vacuum, but takes place within existing institutional structures and often involves the exchange of reasons. These results also 
suggest that scholars who seek to improve our legal system need not advocate wholesale changes (such as switching to an inquisitorial system); rather, they should develop ways to bolster our existing institutions so that they better facilitate truth telling and improve decision making in competitive contexts.

More broadly, our results suggest that scholars should continue to use experimental and survey-based methods to investigate the effects that competition has on decision making in legal, political, and economic contexts. In this study, we took advantage of the strong internal validity associated with laboratory experiments and analyzed the conditions under which jurors can learn from competing experts who they do not know under a variety of institutional arrangements. Because we focused on this one type of competitive context and used one methodological approach, however, our study leaves open the question of whether and when jurors can figure out which of two competing experts is more credible than the other. There is already a large and interesting literature on source credibility, in general, and the perceived credibility of expert witnesses, in particular (Hovland \& Weiss, 1951; Hass, 1981; Cooper et al., 1996; Vidmar \& Seidman Diamond, 2001; Druckman, 2001a, 2001b, 2001c; Chong \& Druckman, 2007). We emphasize that scholars should continue to build on this literature and explore the role that source credibility plays in competitive contexts.

\section{REFERENCES}

Aronson, Eliot, Timothy D. Wilson, \& Marilynn B. Brewer (1998) "Experimentation in Social Psychology," in Daniel T. Gilbert, Susan T. Fiske, \& Gardner Lindzey, eds., The Handbook of Social Psychology, 4th ed. New York: Oxford Univ. Press.

Austen-Smith, David (1990a) "Information Transmission in Debate," 34(1) American J. of Political Science 124.

- (1990b) "Credible Debate Equilibria," 7 Social Choice $\mathcal{E}$ Welfare 75. - (1993) "Information and Influence: Lobbying for Agendas and Votes," 37 American J. of Political Science 799.

Boudreau, Cheryl (2006) "Jurors are Competent Cue-Takers: How Institutions Substitute for Legal Sophistication," 2(3) International J. of Law in Context 293.

Bundy, Stephen M., \& Einer R. Elhauge (1991) "Do Lawyers Improve the Adversary System? A General Theory of Litigation Advice and its Regulation," 79 California Law Rev. 315.

Chong, Dennis, \& James N. Druckman (2007) "Framing Public Opinion in Competitive Democracies," 101 American Political Science Rev. 637. 
Cooper, Joel, Elizabeth A. Bennett, \& Holly L. Sukel (1996) "Complex Scientific Testimony: How Do Jurors Make Decisions?" 20(4) Law EF Human Behavior 379.

Crawford, Vincent, \& Joel Sobel (1982) "Strategic Information Transmission," 50 Econometrica 1431.

Daughety, Andrew F., \& Jennifer F. Reinganum (2000) "On the Economics of Trials: Adversarial Process, Evidence, and Equilibrium Bias," 16(2) J. of Law, Economics, $\mathcal{E}$ Organization 365.

Druckman, James N. (2001a) "On the Limits of Framing Effects: Who Can Frame?" $63 \mathrm{~J}$. of Politics 1041 .

(2001b) "Using Credible Advice to Overcome Framing Effects," 17 J. of Law, Economics, E Organization 62.

(2001c) "The Implications of Framing Effects for Citizen Competence," 23(3) Political Behavior 225.

Fisher, Michael A. (2000-2001) "Going for the Blue Ribbon: The Legality of Expert Juries in Patent Litigation," 2 Columbia Science $\mathfrak{F}$ Technical Law Rev. 1.

Frank, Jerome (1945) Courts on Trial: Myth and Reality in American Justice. Princeton, NJ: Princeton Univ. Press.

Frankel, Marvin E. (1980) Partisan Justice. New York: Hill \& Wang.

Freedman, Monroe H. (1975) Lawyers' Ethics in an Adversary System. Indianapolis, IN: Bobbs-Merrill.

Froeb, Luke M., \& Bruce H. Kobayashi (1996) "Naive, Biased, Yet Bayesian: Can Juries Interpret Selectively Produced Evidence?" 12(1) J. of Laaw, Economics, $\mathcal{F}^{\circ}$ Organization 257.

Hass, R. Glen (1981) "Effects of Source Characteristics on Cognitive Responses and Persuasion," in R. E. Petty, T. M. Ostrom, \& T. C. Brock, eds., Cognitive Responses in Persuasion. Hillsdale: Erlbaum.

Hovland, Carl I., \& Walter Weiss (1951) "The Influence of Source Credibility on Communication Effectiveness," 15 Public Opinion Q. 635.

Jackendoff, Ray (1980) Consciousness and the Computational Mind. Cambridge: MIT Press.

Kaplow, Louis, \& Steven Shavell (1989) "Legal Advice About Information to Present in Litigation: Its Effects and Social Desirability," 102 Harvard Law Rev. 567.

Kim, Hyongsoon (2001) "Adversarialism Defended: Daubert and the Judge's Role in Evaluating Expert Evidence," 34 Columbia J. of Law E' Social Problems 223.

King, Gary, Michael Tomz, \& Jason Wittenberg (2000) "Making the Most of Statistical Analyses: Improving Interpretation and Presentation," 44(2) American J. of Political Science 347.

Kutnjak Ivkovic, Sanja, \& Valerie P. Hans (2003) "Jurors' Evaluations of Expert Testimony: Judging the Messenger and the Message," 28 Law E Social Inquiry 441.

Landsman, Stephan (1983) "A Brief Survey of the Development of the Adversary System," 44 Ohio State Law J. 713. 
Langbein, John H. (1985) “The German Advantage in Civil Procedure," 52 Univ. of Chicago Law Rev. 823.

Lilly, Graham C. (2001) "The Decline of the American Jury," 72 Univ. of Colorado Law Rev. 53.

Lipman, Barton L., \& Duane J. Seppi (1995) "Robust Inference in Communication Games with Partial Provability," $66 \mathrm{~J}$. of Economic Theory 370.

Lupia, Arthur (1992) "Busy Voters, Agenda Control, and the Power of Information," 86 American Political Science Rev. 390.

- (1994) "Shortcuts Versus Encyclopedias: Information and Voting Behavior in California Insurance Reform Elections," 88 American Political Science Rev. 63.

(2002) "Deliberation Disconnected: What it Takes to Improve Civic Competence," 65 Law E Contemporary Problems 133.

(2004) "The Wrong Tack: Who's to Say that People Make Better Decisions in Groups than They Do on Their Own?" 3 Legal Affairs 43.

Lupia, Arthur, \& Mathew D. McCubbins (1998) The Democratic Dilemma: Can Citizens Learn What They Need to Know? Cambridge: Cambridge University Press.

McCubbins, Mathew D., \& Daniel B. Rodriguez (2006) "When Does Deliberating Improve Decisionmaking?" $15 \mathrm{~J}$. of Contemporary Legal Issues 9.

Milgrom, Paul, \& John Roberts (1986) "Relying on the Information of Interested Parties," 17 Rand J. of Economics 18.

Mondak, Jeffrey J. (1993) "Source Cues and Policy Approval: The Cognitive Dynamics of Public Support for the Reagan Agenda," 37 American J. of Political Science 186.

Posner, Richard A. (1999) "An Economic Approach to the Law of Evidence," 51 Stanford Law Rev. 1477.

Pound, Roscoe (1906) "The Causes of Popular Dissatisfaction with the Administration of Justice," 29 Reports of the American Bar Association 395.

Schacter, Daniel L. (2001) The Seven Sins of Memory: How the Mind Forgets and Remembers. Boston, MA: Houghton-Mifflin.

Seidman Diamond, Shari (2003) "Truth, Justice, and the Jury," 26 Harvard J. of Law Ẽ Public Policy 143.

Sher, Shomi, Craig R. \& M. McKenzie (2008) "Framing Effects and Rationality," in M. Choter \& N. Oaksford, eds., The Probabilistic Mind: Prospects for Bayesian Cognitive Science. Oxford: Oxford Univ. Press.

Shin, Hyun Song (1998) "Adversarial and Inquisitorial Procedure in Arbitration," 29(2) RAND J. of Economics 378.

Sniderman, Paul M., Richard A. Brody, \& Philip E. Tetlock (1991) Reasoning and Choice: Explorations in Political Psychology. New York: Cambridge Univ. Press.

Sniderman, Paul M., \& Sean M. Theriault (2004) "The Structure of Political Argument and the Logic of Issue Framing," in W. E. Saris \& P. M. Sniderman, eds., Studies in Public Opinion. Princeton, NJ: Princeton Univ. Press.

Sobel, Joel (1985) “A Theory of Credibility," 52 Rev. of Economic Studies 557.

Tomz, Michael, Jason Wittenberg, \& Gary King (2003) CLARIFY: Software for Interpreting and Presenting Statistical Results, ver. 2.1. Stanford University, University of Wisconsin, and Harvard University. Available at http://gking.harvard.edu/.

Tullock, Gordon (1975) "On the Efficient Organization of Trials," 28 Kyklos 745. 
(1980) Trials on Trial: The Pure Theory of Legal Procedure. New York: Columbia Univ. Press.

Vidmar, Neil, \& Shari Seidman Diamond (2001) "Juries and Expert Evidence," 66 Brooklyn Law Rev. 1121.

Walpin, Gerald (2003) "America's Adversarial and Jury Systems: More Likely to Do Justice," 26 Harvard J. of Law $\mathcal{F}$ Public Policy 175.

Weigend, Thomas (2003) "Is the Criminal Process About Truth? A German Perspective," 26 Harvard J. of Law Eं Public Policy 157. 